\title{
AEROMAGNETIC MAP OF THE PALMER QUADRANGLE HAMPDEN, HAMPSHIRE, AND WORCESTER COUNTIES MASSACHUSETTS
}

\author{
GEOPHYSICAL INVESTIGATIONS \\ MAP GP-617
}

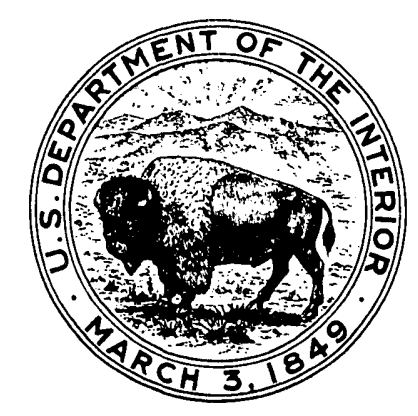

PUBLISHED BY THE U. S. GEOLOGICAL SURVEY WASHINGTON, D.C. 